\title{
JUAN RUIZ, UN HOMBRE DE NUESTRO TIEMPO
}

I.

Alguien. Cualquiera. Nos cuenta una historia. Es la historia del rico emperador de las viandas. Es la historia de una escuálida hembra, adusta como el tiempo que anuncia. De un reto. Son ejércitos de chuletas y de pechugas. Son sardinas, boquerones y arenques. Trabados en confusa reyerta. En batalla encarnizada.

El emperador de la crápula festiva, sañudo, prisionero, humillado, se retracta y se confiesa.

Es obligado a cumplir penitencia...

Pues que de penitençia vos fago mençión, repetirvos querría una chica liçión... (c. 1132)

Es el Arcipreste.

DE LA PENITENÇIA QU' EL FRAIRE DIO A DON CARNAL E DE CÓMO EL EL PECADOR SE DEVE CONFESSAR E QUIEN HA PODER DE LO ABSOLVER.

Es don Carnal. Es doña Cuaresma. Es la ocasión de dirimir. ¿Por qué no? jurídica y canónicamente las competencias de confesores y de penitentes, de los derechos de los unos y de los deberes de todos; de bibliografía especializada; de credenciales y privilegios papales, cardenalicios, arzobispales... Es el Libro de Buen Amor. Es Juan Ruiz. Cualquiera. Arcipreste de Hita. De alguna misteriosa manera y modo, somos nosotros.

El Libro del Arcipreste nos sacude. Han transcurrido seis siglos y aún somos nosotros... Pero su ímpetu y su vigor hace tiempo que nos han abandonado. Sólo experimentamos la "exageración" de un poeta cuyo sentido de la medida literaria es capaz de acoger los elementos más dispares en una cabal y sola visión del mundo.

Súbitamente, percibimos la rara exigencia de la realidad en que el poeta se sumerge y bracea; y esto, presumiblemente, nos desorienta.

DE CUÁLES ARMAS SE DEVE ARMAR EL CRISTIANO PARA VENCER EL DIABLO, EL MUNDO E LA CARNE...

Como por azar o descuido, entre el epitafio blasfemo dedicado a Urraca y el encendido elogio de las virtudes que las dueñas chicas han, aparentemente desconectada de la hebra narrativa, esta genuina amonestación se imbrica, no obstante, a la intriga mediante la ironía radical que alienta la obra entera, configurando un todo coherente. Premeditado. Moderno. Entonces, el libro del Arcipreste se nos antoja la obra de toda una vida, la suma 
de la experiencia de un tiempo entero. Un tiempo cifrado en que la sorpresa, los contrarios fundidos y abrazados manifiestan la secreta voluntad del creador...

Quiérovos abreviar la mi predicaçión

que siempre me pagué de pequeño sermón

e de DUEÑA PEQUEÑA e de breve razón... (c. $160 \mathrm{abc}$ )

Un empeño de totalidad. Como Jacques Joset recuerda en el prólogo a su edición del libro (Madrid, 1974, XXIV-XXVII). Un intento supremo de asumir artísticamente la entera realidad, mudable y tremendamente enmarañada, del hombre y de su entorno.

Apariencia y realidad. Experiencia múltiple y diversa del mundo. Bruma caleidoscópica detrás de la cual se esconde la verdadera esencia humana, aquellos elementos que nos explican definitivamente... Enigma a descifrar. A desvelar. A entender: INTELECTUM TIBI DABO.

Para Juan Ruiz. Cualquiera. En la lucidez la única vía integradora de acceso a un mundo complejo y confuso, que la muerte ya no justifica ni explica; cuando la condición humana no se entiende más en términos de ultratumba...

¿Adó te me han levado? No sé cosa çertera:

nunca torna con nuevas quien anda esta carrera. (c. 1569 cd)

La adquisición de conciencia es un arduo camino que conduce a la soledad. Y en soledad la síntesis resulta improbable o imposible...

Soledad bilateral. Revelación artística. Dialéctica abierta. Cruel, a veces. En la que el único punto de encuentro se da en el resbaladizo terreno de lo anfibológico; esto es, del incierto sentido.

El gesto equívoco y cómplice que Juan Ruiz. Cualquiera. Nos dispensa tiene su origen en la no resolución de las situaciones propuestas en el texto o en la conclusión ambigua y sugerente de las mismas.

¿Cómo recoger satisfactoriamente todo esto en una explicación global del texto? ...

La concepción didáctica del Libro, cualquiera que sea el matiz que haya querido darse a tal concepto, ha obstaculizado durante un tiempo prolongado la cabal comprensión e interpretación de los antecedentes propuestos... ${ }^{1}$

Fue Américo Castro quien, tras la fragmentación y la diversidad, adivinó "una constante de sentido", "una visión estructurante de la realidad poetizada", que, para él, no era otra que "la tensión del vivir cotidiano y voluntarioso", tema primordial del Libro de Buen Amor. La necesidad de amor enfrentada a fuerzas sociales, existenciales e incluso

1 Recordemos que $M^{\mathrm{a}} \mathrm{R}$. Lida, aun reconociendo que la contradictoriedad esencial del Libro de Buen Amor (en continuación LBA) posee sus raíces más profundas en su naturaleza mudéjar, frente a las nociones de unidad y categorías artísticas grecorromanas, pensaba que la "la importancia indudable de los debates está caprichosamente abultada" y que "el libro no autoriza a ver en el Arcipreste un teólogo o un moralista torturado por su visión dualista excepcionalmente honda y original". Ma Rosa Lida, "Nuevas notas..." en: Estudios de Literatura española y comparada, Buenos Aires, 1966, pp. 14-91. 
cósmicas, que lo impiden o estorban. El amable universo islámico, con su eterno juego de apariencias de apariencias, enfrentado al cerrado universo cristiano del medievo... 2

Desde otra perspectiva, Claudio Sánchez Albornoz vinculó la radical ironía con que están tratados los materiales del libro, al proceso de conformación de la conciencia burguesa en la Castilla del siglo XIV... ${ }^{3}$

Más adelante, Anthony N. Zahareas nos mostraría convincentemente cómo ese tratamiento irreverente de los esquemas retóricos y didácticos heredados del siglo anterior, expresa una intransferible y personal visión del mundo... 4

Existencia sujeta a profundas mutaciones; causa de angustia y de desorientación. Deseo urgente de goce. De felicidad inmediata. Eficaz. ${ }^{5}$

Luego el Libro del Arcipreste es la expresión artística de una fuerte personalidad en tenso conflicto con el medio; es este dato el que nos acerca a su razón encubierta: alcanzando sí, un cierto nivel explicativo.

Recuperando su historicidad, la estructura interna del texto, laberíntico, entramado de dualidades, viene a ser significativa poéticamente: como manifestación de un mundo diverso de aquel que suscita y promueve las obras del viejo mester... ${ }^{6}$

En el universo clerical, no cabe el equívoco.

\section{Múltiples lecturas de una seducción}

\section{DE CÓMO TROTACONVENTOS CONSEJÓ AL ARCIPRESTE QUE AMASE ALGUNA MONJA E DE LO QUE CONTEÇIÓ CON ELLA.}

Analicemos desde esta perspectiva un episodio clave en este frondoso enramado que es el Libro de Arcipreste. Aquel que protagoniza doña Garoza. La monja. Alaroza. La novia.

Setecientos versos, ciento setenta y cinco coplas de raudal literario...

2 Américo Castro, Realidad Histórica de España, México, 1954. Y "El Libro de Buen Amor del Arcipreste de Hita" en: «Comparative Literature» IV (1952), Eugene (Oregon).

3 Claudio Sánchez Albornoz, España, un Enigma Histórico, Buenos Aires, 1956, I / 530-553.

4 Anthony N. Zahareas, The Art of Juan Ruiz, Archpriest of Hita, Madrid, 1965. Confrontar en tal sentido la obra de Antonio Gómez Moriana, La Subversion du Discours Rituel, Longueil - Quebec, 1985.

5 Cfr. Julio Rodríguez Puértolas, “Juan Ruiz, hombre angustiado" en: Literatura, Historia, Alienación, Barcelona 1976, 71-103. Y Juan Ruiz, Arcipreste de Hita, Madrid, 1978.

Y Juan Carlos Solomón, Michael y Temprano, "La individualidad, el bien eficaz y el dilema de Juan Ruiz" en: Boletin de la Biblioteca Menéndez Pelayo, Santander, 1985, 15-35.

6 Una especial atención merecería la naturaleza del léxico utilizado por el Arcipreste; así como el modo de utilización del mismo. O la flexibilización de las formas métricas propias del Mester de Clerecía. Américo Castro, Realidad Histórica de España, obra citada, p. 392. También, Anthony Zahareas, The Art of Archpriest of Hita, Madrid, 1965; y Leo Spitzer, "En torno al arte del Arcipreste de Hita" en: Lingüistica e historia lite-raria, Cap. 3., $2^{2}$, Madrid, 1961. 
Como es sabido. Trotaconventos aconseja al arcipreste protagonista, que después de un nuevo fracaso siente la comezón, una vez más, de la soledad, probar el amor de una monja: garantía de los placeres más delicados, de los filtros de amor más refinados...

Lo verdaderamente relevante de esta introducción es que se ha construido con todos aquellos tópicos que configuran la tradición de un tema medieval, del amor de las monjas, de amplio eco en la literatura castellana.

Sin embargo, como significó la profesora Lida de Malkiel, todas las expectativas creadas se quiebran pronto...

Aquesta buena dueña avíe seso bien sano, era de buena vida, non he fecho liviano... (c. $1347 \mathrm{ab}$ )

Doña Garoza es una mujer inteligente; no es la monja casquivana que esperábamos. Cuando se enfrenta a Trotaconventos, un tema anunciado con todos los abalorios del folklore, se ve sacudido en sus fundamentos y proyectado a esferas de significación insospechadas.

Es aquí donde se entabla el más admirable, brillante e intenso debate apologético de nuestra Edad Media. Incesante viaje de ida y vuelta que nos lleva de lo particular a lo general, de lo genérico a lo concreto, provocando repetidas rupturas de gestos apuntados; de temores fundados y finalmente ignorados. Viejos apólogos y fábulas tradicionales sometidos a lecturas imprevistas, tensadas hasta el límite sus posibilidades significativas existenciales. Material narrativo que, no lo olvidemos, ha sido utilizado en esa crucial coyuntura de la historia de Castilla por el Infante don Juan Manuel, con un fin y un sentido diametralmente opuestos.

Pues, si se me permite el excurso, hay un yo instrumental y cerrado, integrado por una visión del mundo que se sustenta en una aspiración antigua de dominio y de servidumbre; que se manifiesta como una especial violencia individual, y que se enfrenta a otro yo que es manifestación de una conciencia conflictiva, abierta y dialéctica del mundo y de la existencia entera.

Para don Juan Manuel, la realidad entera es un objeto de dominio, la conciencia se manifiesta como conciencia de dominación del hombre sobre la mujer, del hombre, como género, sobre la naturaleza; de cada individuo sobre los demás individuos, de unos colectivos, digamos las clases, sobre los otros: de los cristianos sobre los "moros", de los amos sobre los siervos... Y todo a partir de una falsa conciencia de sí mismo, en los términos elaborados por Erich Fromm, cuyo origen habría que buscarlo en la ciega confianza del infante de Castilla en las potencias de un yo emergente y voraz, ajeno por completo a la experiencia amorosa.

Pero el ejercicio del poder resulta un hecho básicamente alienante no tanto para quienes lo soportan, como para quien lo ejercita. Existencialmente, don Juan Manuel se nos aparece como un individuo incapacitado para el amor tal como lo entiende Juan Ruiz, esto es, para el goce libre y espontáneo de esa intima relación entre los seres humanos. 
En el Libro del Arcipreste, sin embargo, nos encontramos con una conciencia que se manifiesta como conflicto doloroso; liberada de la urgente necesidad de dominio, la conciencia del Arcipreste concibe el mundo como escenario de la conflictiva experiencia del yo, sujeto a fuerzas amenazadoras y destructivas.

Si las relaciones de poder determinan la obra de uno; el asombro del misterio de la existencia anima la del otro.

La estructura de los textos y la retórica a partir de la que se articulan los mismos, es sabido, son elementos que nos transmiten, tanto como los contenidos, mensajes de carácter ideológico; la utilización, pues, de los apólogos y de las colecciones de cuentos orientales, a mi modo de entender, simples manuales de conducta práctica en su origen, debería considerarse como un modo de "apropiación didáctica", ideológicamente "militante", $\mathrm{y}$, en tal caso, extraordinariamente significativa, por los autores del Medioevo. De manera que, si el Infante se apropia de la tradición apologética desde una perspectiva orgánica en la que se aprecia una cierta incapacidad para la ironía, Juan Ruiz lo hace desde otra, esencialmente distanciada y rabiosamente personal.

La retórica del Infante es aleccionadora, unilateral o unidireccional, sustentada en un esquematismo cerrado y en la reiteración sin concesiones; en tanto que el Libro de Buen Amor presenta una estructura abierta y una "desorganización" aparente, aún más significativas, si se tiene en cuenta la extremada conciencia del LIBRO que poseen ambos autores.

No es menor la conciencia de estilo; por lo que, detrás del oscuro y "sotil" modo, no se esconde más que una calculada instrumentalización del arte por una minoría, precisamente aquella que detenta el poder político y social.

Por el contrario, tras las continuas advertencias del Arcipreste, no habría otra cosa que una firme convicción en la capacidad de todo ser humano para penetrar vital e intelectualmente en el sentido oculto de la realidad y del tiempo de los hombres.

De cualquier modo, una honda fractura se ha abierto en el desarrollo del episodio; la misma que separa el prólogo en prosa del resto del libro, ${ }^{7}$ dejando al aire lo más específico y característico de su transcurso creativo.

La dialéctica más radical se adueña de la estructura y de los contenidos. Una vez más, formas literarias tradicionales: el apólogo y el debate, en este caso; se convierten en instrumentos de nuevos modos de decir y pensar; plenos de significados originales, que abren la puerta a lecturas diversas y multivalentes. De tal modo que los materiales con que se constituye la base argumental de la disputa se encuentran tan distantes del amable divertimiento, juguetón y despreocupado; como de la pía didascalia clerical. ${ }^{8}$ Por el

7 Villanueva Márquez, "El Buen Amor" en: «Revista de Occidente» 27 (1965), pp. 281-282; señala y analiza la diferente utilización del concepto de "buen amor" que Juan Ruiz hace en el prólogo en prosa y en el resto del libro.

8 Una vez más, habría que mencionar a Julio Rodríguez Puértolas, “Juan Ruiz, hombre angustiado”, op. cit., pp. 71-103. Y Américo Castro, "El libro de Buen Amor del Arcipreste de Hita”, op. cit., pp. 193-213. Quienes, 
contexto en que se integran, ya sea el del Libro considerado en su totalidad, ya sea el del episodio, como unidad vinculada a aquel, son apasionada sustancia de una sincera reflexión sobre las quebradizas relaciones humanas en un mundo percibido como un ámbito hostil y engañoso.

$\mathrm{Si}$, de una parte, se teme la traición y la ingratitud...

ENXIEMPLO DEL ORTOLANO E DE LA CULEBRA ...

el individualismo extremo y egoísta ...

ENXIEMPLO DEL GALGO E.DEL SEÑOR ...

de amigo sin provecho non ha el ome cura. (c. $1364 \mathrm{~d}$ )

Si se desconfia y se recela del engaño que achecha ...

ENXIEMPLO DEL MUR DE MONFERRANDO E DEL MUR DE

GUADALAJARA ...

Si se vive temerosamente el conflicto existencial a que nos induce la alternativa seguridad/inseguridad en una realidad fundalmente insegura y peligrosa. $\mathrm{Y}$ se siente miedo. Miedo a la posesión de bienes o de valores codiciados por los otros...

Con paz e segurança es rica la pobreza ... (c. 1384 a)

De la otra, se arguye la necesidad del riesgo ...

ENXIEMPLO DEL GALLO QUE FALLÓ EL ÇAFIR EN EL MULDAR ...

el amor y el placer como los dones divinos más preciados ...

A quien Dios ventura e non la quier tomar,

non quiere valer algo nin saber nin pujar ... (c. $1391 \mathrm{ab)}$

Y la acción. La acción como antídoto del miedo

ENXIEMPLO DE LAS LIEBRES ...

la acción como promesa; tal vez, la sola alternativa.

La conducta de la vieja es astuta y sutil, como la de quien comprende y actúa en consecuencia. El progresivo cambio psicológico que experimenta la monja, tentada por el eco inocente de la vida, es candoroso, como quien claudica, y a pesar de todo, confia.

El terco anhelo de seguridad en un mundo sin efugios, duro y despiadado; el convencimiento de que es preciso salvaguardar a toda costa la propia libertad individual para sobrevivir; de que ésta no puede hipotecarse, aun a riesgo de soledad, en las relaciones con los otros: actitudes todas que se encuentran agazapadas en los argumentos de la monja, son manifestacione de una realidad nueva: y vieja a un tiempo, que causa miedo y desorientación a todos aquellos que no participan activamente en su advenimiento y concreción.

Además, aún no se poseen todas las claves que más tarde permitirán a los hombres de ese nuevo orden interpretarlo. Sería en tal sentido, y no en otro, en el que Juan Ruiz. Cualquiera. Es un hombre del medievo. Pues, por otra parte, el convencimiento de que el miedo nos aleja de la vida, inmovilizándonos; la seguridad de que debemos aprovechar la ocasión única, el instante irrepetible; de que el placer, en suma, es una alternativa posible

frente al concepto de "jovialidad absoluta y despreocupada" de la obra de Arcipreste, han señalado y hecho hincapié a lo "seriamente humano" del $L B A$. 
y deseable: coartadas ideológicas de la naciente sociedad urbana; trampas que hábilmente tiende la vieja Urraca, nos hablan de un Juan Ruiz. Cualquiera. Que asume poéticamente aquellos valores de modo contradictorio y problemático; porque la elusiva realidad en que vive es en sí misma contradictoria y problemática; en busca aún de una síntesis histórica que, en Castilla, sólo se conseguirá parcial y tardíamente.

Veamos sin perder nunca esta perspectiva, cuál es su conclusión y desenlace. Se ha dicho que doña Garoza cede finalmente ante los hábiles argumentos esgrimados por la vieja. Víctima de un aparente engaño, la entrañable monja nos conmueve.

Sin embargo, doña Garoza cede finalmente ante realidades más potentes aún que la mañosa sagacidad de una tercera. Se rinde al imperio de la palabra, a la fuerza abrumadora del deseo. VERBUM TIBI DABO.

La palabra, fundamento aparente de la comunicación, a menudo se convierte en obstáculo insalvable.

Puede ser bálsamo que nos alivie ...

... ayuda otra non me queda, sinon lengua e parlares. (c. $649 \mathrm{~d}$ )

Puente tendido hacia el otro ...

... Ya vo razonar con ella, quierol dezir mi quexura,

porque por la mi fabla venga a facer mesura;

diziéndole de mi coitas, entenderá mi rancura;

a vezes de chica fabla viene mucha folgura. (c. 652)

Eficaz instrumento del deseo; infatigable fustigadora de la fantasía...

... Quanto más malas palabras ome dize e las entiende,

tanto más en la pelea se aviva e se enciende;

quantas más dulces palabras la dueña de amor atiende,

a tanto más doña Venus la enflama e la ençiende. (c. 856)

O vía de conocimiento ...

... Por la fabla se conosçen los más de los coraçones ... (c. 677 a)

$\mathrm{Y}$, sin embargo, ino es la palabra mal medida la causa de la ruptura entre el arci-


sutil instrumentación de la misma?

Para Juan Ruiz. Cualquiera. Las palabras, tanto como cauces de alteridad, son causa frecuente de incomunicación. Tanto como vía de conocimiento, son instrumentos de dominación y fuente de conflictos. Es el carácter dual e indeciso del universo poético del Arcipreste. Pues si son la manifestación más original del yo; si es la palabra individual redescubierta materia disolvente del orden orgánico, no es de extrañar que sea sentida de modo conflictivo: juguete poderoso y apasionante, pletórico de posibilidades expresivas, que primero se tantean y después, una vez ensayadas, se llevan hasta sus últimas consecuencias.

Agente perturbador de las relaciones humanas, la voz colectiva del Mester ha dado en las singulares voces discordantes de Juan Ruiz. Cualquiera. Arcipreste de Hita; de Sem Tob de Carrión; y de don Juan Manuel, Infante de Castilla: individuos a caballo entre dos 
realidades contrapuestas; víctimas a menudo del novedoso recreo, cuyas reglas, además, no son del todo inocentes.

Y así parece intuirlo el Arcipreste, cuando nos previene para que las palabras sirvan a la intención y no la intención a las palabras; para que no se nos adueñen, y encubran el verdadero sentido de la realidad, embaucándonos, enajenándonos.

Con el fin de comprender sus múltiples significados, se nos ha concedido la inteligencia; para que vislumbremos (si es posible) tras los discursos sobre la realidad, la realidad misma; o dicho de otro modo, para entrever en el laberinto del discurso poético sendas de penetración y de reconocimiento que amplíen nuestros confines existenciales y vitales: fronteras sustancialmente no retóricas.

\section{LA MUERTE, SÍNTESIS VERDADERA E INEXCUSABLE. DE COMO TROTACONVENTOS ...}

Oteóme de unos ojos que paresçían candela:

yo sospiré por ellos, diz mi coraçón: “iHela!"

Fuime para la dueña, fablóme e fabléla, enamoróme la monja e yo enamoréla.

Estamos en el reborde; es la copla 1502 ... Es el encuentro con Alaroza. La novia. La muerte acecha.

Una interjección: “iHela!", vértice ideográfico y sonoro de la incontenida expresión de júbilo vital y sacrílego que embarga al protagonista, deviene en espontáneo conjuro de todos los deseos, de todas las esperanzas, de todas las ilusiones nunca satisfechos; de las innumerables búsquedas inútiles; de los incontables fracasos que han jalonado su existencia poética. Inevitable grito de plenitud ante lo que parece ser el definitivo encuentro con el amor.

El universo del Arcipreste, presidido por un Dios que es, a un tiempo, fuente y principio del amor y del placer, se justifica finalmente con el "limpio amor" de Alaroza, la novia.

Algunos han visto, aunque desde ópticas muy diferentes, en este episodio el único ejemplo de "buen amor" que hay en el texto. Jacques Joset, ed. cit., Madrid 1974, Nota 1507 c. Y Márquez Villanueva, art. cit., p.282. Aún así, el dilema sigue en pie. ¿En qué consiste realmente el "buen amor"? ¿en la pura contemplación del objeto amado o en el amor simplemente realizado, tal como Solomon y Temprano señalan al analizar el concepto de "bien eficaz" como eje de la moral ruiziana.

Una vez más lo único que nos resta es el vago sabor de la sugerencia, de lo sinuosamente evocado, de lo nunca denotado o explicado. Intuimos apenas que la contemplación y el deseo se entremezclan y confunden, que las fronteras se diluyen y desaparecen; que todo está aún por explicar. Es el pasmo goliárdico que alienta la confusión y la extrañeza de los clérigos bebedores y rebeldes, entremezclado con la elegante mística de la concupiscencia sufi. ¿Qué papel les aguarda - a los de Talavera también - en una realidad que fragua sus cimientos en una nueva y diversa división del trabajo; qué hacer, cómo vivir, 
en una cultura secularizada, mundanizada, que ha herido de muerte a la institución de la que orgánicamente forman parte, y que ahora exige de sus miembros un reajuste de su situación con respecto a la naciente sociedad civil? ${ }^{9}$ Individuos que repentinamente se han descubierto como sujetos de deseo, se ven violentados, forzados a la frustración sistemática de sus pulsiones más íntimas y apremiantes. La ironía, el equívoco, el amargo sarcasmo. Premeditados. Necesarios. Son inevitables. El arte es triste, se ha dicho. También inevitable. Como la huida. Como la derrota.

La burla que oyeres non la tengas en vil ... (c. 65 a)

De todos los instrumentos yo, libro, só pariente

bien o mal qual puntares, tal diré ciertamente;

qual tú dezir quisieres, ý faz punto, ý tente;

si me puntar sopieres sienpre me avrás en miente. (c. 70)

Pues más allá del sinuoso y blando dominio del estupor, de la indecisión y de la duda, se encuentra el reino de la Muerte. Incontestable. Imponente. Estúpido. E insolente.

Atal fue mi ventura que, dos meses pasados,

murió la buena dueña: ove nuevos cuidados;

a morir an los onbres, que son e serán nados:

¡Dios perdone su alma e los nuestros pecados! (c. 1506)

La muerte, causa primera e inmanente, es también síntesis última y verdadera. Después, la soledad y el fracaso definitivo -_."ove nuevos cuidados"-.

El famélico espectro ha marcado los límites del gran arabesco imaginado por Américo Castro. 10

Ha habido dos sistemas de valores enfrentados, dos visiones del mundo en lucha; finalmente ha habido decisión por uno de ellos, el más arriesgado y voluntarioso, pero esta decisión ha concluido con el destello fugaz del deseo y con la muerte. Después, tan sólo la decadencia y el agotamiento.

De todo lo dicho hasta ahora hay dos hechos, pues, que se destacan y que son especialmente interesantes para la comprensión crítica del texto; uno, que el Libro de Buen Amor es una obra de complejidad artística indudable; otro, que su autor poseía exacta conciencia de ello, y, según creo en tal medida que dicha complejidad constituye un objetivo literario ciertamente asumido por éste.

... no l'dedes por dineros vendido ni alquilado, ca no ha grado nin gracia el buen amor conprado.

Fizvos pequeño libro de testo, mas la glosa non creo que es chica, ante es bien grand prosa, que sobre cada fabla se entiende otra cosa

9 Ver para todo ello el artículo citado de Juan Carlos Temprano y Michael Solomon, "La individualidad, el bien eficaz y el dilema de Juan Ruiz" en: «Boletín de la Biblioteca Menéndez Pelaya». Santander, 1985, pp. 15-35.

10 Cfr. Rafael Lapesa, "El tema de la Muerte en el Libro de Buen Amor" en: De la Edad Media a nuestros dias, Madrid, 1967, pp. 53-75. 
sin lo que se alega en la razón fermosa.

De la santidat mucha es bien liçionario,

mas de juego e de burla es chico breviario;

por ende fago punto e cierro mi armario:

séavos chica fabla, solaz e letüario. (cs. 1630-32)

\section{Juan Ruiz, hombre sin fe: el arte necesario}

Es indudablemente por todo ello por lo que se nos exige inteligencia y no fe: esto es, la aceptación incondicional de un sistema de valores o de una visión del mundo en el que todo, el bien y el mal, la belleza y la fealdad, la justicia y la injusticia, la vida y la muerte, está explicado desde el principio; todo fatalmente ajustado en el alucinado mecanismo de la creación.

Se nos exige inteligencia, porque ya no basta la fe. A cambio, se nos ofrece lucidez; pero el precio es la conciencia dispar de una realidad deshumanizada en sus fundamentos, culminada por la muerte. Si esto nos provoca angustia, si el precio de la inteligencia es el dolor, nos queda la ironía, el humor cínico y burlón, o el sarcasmo. Pues la inteligencia se salva mediante la risa o la sonrisa, aunque no eviten, a veces, el llanto o la lágrima furtiva. Esta sería, a fin de cuentas, la propuesta que nos hace el Arcipreste en su obra, algo tan pedestre y vulgar, tan fácil como reír para no llorar, para no olvidar que estamos evitablemente vivos.

Ya no hay sistemas inviolables, indiscutibles; uno ha sido radicalmente cuestionado, otro simplemente aún no es. Juan Ruiz. Cualquiera. Hombre moderno. Cercano a nosotros. Hombres esencialmente sin fe. No acepta la muerte como justificación escatológica de la vida. Del dolor.

Por otra parte, si la concepción ruiziana del arte descansa sobre la consideración consciente de éste como instrumento al servicio de la voluntad individual del Yo creador y de sus pasiones más íntimas, esto quiere decir que nos encontramos de nuevo ante un producto cultural radicalmente distinto de aquellos que, de una u otra forma, responden a los modos de hacer y de concebir lo artístico propios del viejo Mester.

Se ha llegado incluso a plantear la existencia de un plan previo en la elaboración del Libro; es algo que difícilmente podremos demostrar. Pero lo que está fuera de toda duda es la coherencia artística del conjunto de la obra, su cuidada composición interna. Que elementos textuales tan diversos como su característica utilización del léxico, basada en la desviación semántica controlada; el uso del estilo indirecto, de la narración y del comentario en una forma tal que supone la consolidación del diálogo (Yo dialéctico) en nuestra literatura; la perfecta gradación en las respuestas de la mora; la estudiada y compleja estructura interna del sermón sobre las armas del cristiano; la utilización del mismo código metafórico para describir a doña Endrina y a doña Garoza; o el componente lírico del Libro, adquieren una significación que va más allá de la simple ejercitación retórica.

Desde el prólogo en prosa, hasta las coplas finales, Juan Ruiz. Cualquiera. Nos habla repetidamente de la estima que su potencial artístico le merece; y sobre todo de la com- 
plejidad intencionada de su obra. Hasta ese momento, pocos autores han reflexionado tanto sobre su propia creación y menos aún han integrado dicha reflexión en el texto como componente literario esencial del mismo: prólogo en prosa 152-153; coplas 65-70, $1498 \mathrm{~b}, 1631$ y $1634 \mathrm{~d}$.

El Libro del Arcipreste no ha sido fruto del azar; Juan Ruiz. Cualquiera. Comprende dos siglos antes que Cervantes y domina, en la medida que puede hacerlo un hombre del siglo XIV en Castilla, ${ }^{11}$ los mecanismos esenciales del fenómeno literario por excelencia: el texto como ámbito autónomo de relaciones, que necesita de la complicidad del lector para adquirir total sentido "vital" y "artístico" (c. 1507d, c. 1629). Por primera vez en Castilla, literatura y vida forman un binomio indisociable.

En el vértice de mundos encontrados, no hay demasiadas respuestas, por eso todo en este libro se resuelve en términos de confrontación y de contraste. Confrontación alegórica, narrativa, ideológica y dialéctica:

Don Carnal contra doña Cuaresma

El Arcipreste contra don Amor

Contra las Serranas

Doña Garoza contra Trotaconventos

EI vicio contra la virtud... batallas, peleas y debates.

El contenido agónico de la mayor parte de las fábulas; los continuos

desniveles en la estructura del Libro; el contrapunto lírico o el verso frente

a la prosa rimada.

Pero hay un conflicto que anuncia todos los demás conflictos, constituyéndolos substancialmente. No es de naturaleza cósmica, tampoco estrictamente material; es una disfunción existencial que procede, sin embargo, de contradicciones fundamentales en los ámbitos de lo social y de lo cultural. Es el permanente combate entre lo que desde diferentes perspectivas, se ha denominado (Cernuda) la Realidad y el Deseo. Contradicción original de la reciente sociedad capitalista, únicamente posible en ella. Porque sólo en la nueva sociedad es posible el deseo y solamente en ella es posible su frustración existencial.

En el viejo orden feudal tal conflicto no era posible, al menos planteado en términos artísticos y literarios, porque éste es propio de individuos con una fuerte conciencia de sí mismos y de su entorno vital como entramado de relaciones conflictivas... En un medio que lo promueva y lo estimule, dinámico y móvil; radicalmente distinto del modelo organicista y estamental aristocrático, en el que los hombres poseen un Yo colectivo, cerrado y mítico, satisfecho en sí mismo e "integrado" quel lo impide o lo estorba; en el que la movilidad social o existencial de la mayoría no se contempla como posibilidad, ni aun como necesidad o aspiración.

11 Américo Castro en $L R H E$, pp. 385-387 aborda las causas de las limitaciones que Juan Ruiz tiene en la caracterización de sus personajes. También, $M^{2}$ Rosa Lida, "Nuevas Notas..." en obra citada, pp. 18-19. 
En tal sentido, es un conflicto propio del hombre moderno, que sintiéndose "separado" (Erich Fromm) del mundo y de los otros hombres, añora la plenitud del Paraíso perdido.

Juan Ruiz. Cualquiera. Es el primer artista que en Castilla ha sentido esta angustia y este anhelo, manifestándolo de modo poético. Por eso, acaso, ... su obra nos afecta tan íntimamente aún hoy, más que cualquier otra obra de nuestra literatura medieval, si exceptuamos el postrero y monumental texto que es La Celestina de Fernando Rojas. Cualquiera.

Esto, por otra parte, fue, hace tiempo, intuido por Américo Castro, que cuando nos habla de la "tensión del vivir cotidiano y voluntarioso" como "visión estructurante de la realidad poetizada" y como "tema primario" del Libro del Arcipreste, hace especial hincapié en el hecho de que esta tensión, protagonista del texto, es consecuencia, más que de la contradicción vicio/virtud, de la planteada entre impulsos vitales/y obstáculos que se oponen a la realización plena de los mismos. $O$ dicho de otro modo, entre una necesidad perentoria de amar y fuerzas que, como la costumbre, el hado, la naturaleza o la moral dominante, positivas o negativas, en cualquier caso, son totalmente ajenas a la voluntad individual de los hombres.

¿Se trata del "fatal" universo mudéjar que turba el macizo andamiaje escolástico? Quizás.

De cualquier forma, Juan Ruiz sintió con aprensión este conflicto primordial de la condición humana (cs. 44-45, cs. 687-694, c. 882, cs. 917-918, cs. 1332-1507); con dolorosa lucidez supo que sólo el cumplimiento del deseo abre las puertas del placer inocente, del goce sin culpa ni pecado (c. 71 y ss., cs. $108-112$, c. 763 , c. 1511 a, c. 1630 , especialmente desde la perspectiva de Márquez Villanueva, en "El buen amor", «Revista de Occidente», 27 (1965), pp. 269-291). Esta es al cabo la aspiración absoluta del libro, el imposible restablecimiento de la gracia adánica. Poder renombrar el mundo, a las criaturas y las cosas, y rehacer sus fundamentos y medidas. ${ }^{12}$

Sin embargo, la condición humana es una realidad inabarcable y el destino, un curso fatal ajeno siempre a la voluntad de los hombres. La comunicación ha sido pervertida en sus fundamentos; la palabra, su principal instrumento, es fuente de continua tensión. La mediación se hace inevitable. El fracaso significa soledad. ${ }^{13} \mathrm{Y}$ el dolor ni se explica ni se

12 “A todos nos gustaría ser como Adán y poder ponerle nombre, una a una, a todas las cosas de la creación. El único problema es que los animales ya tienen todos nombres." Orson Welles, Suplemento "Artes", Nㅛ 121 del diario "El País». Cfr. Alejo Carpentier, "Problemática de la actual novela latinoamericana", en: Tientos, diferencias y otros ensayos, Barcelona, 1987, 7-28, p. 16.

13 En cuanto a la conciencia del fracaso y de sus consecuencias; de la muerte y de la decadencia, además de releer las coplas 109 y $110 ; 161 ; 329$ y ss.; 575 a $577 ;$ y 843, donde tal conciencia se hace explícita, es interesante comprobar algunos datos que, como el temor reiterado y obsesivo de doña Endrina y de doña Goroza a ser engañadas, el contenido de fábulas como la del zorro atrapado en la ciudad cercada o los síntomas de decadencia y decrepitud en la última aventura amorosa emprendida, nos indican que, detrás del fracaso continuado, hay algo más que admonición y moralización devota; tal vez, lúcida conciencia de la incapacidad existencial de 
trasciende. Hay barreras sociales, cósmicas y existenciales que se interponen en el camino de la felicidad. Al Arcipreste, a cualquiera de los dos, al ser humano. Cualquiera. Y el protagonista de la fábula, únicamente le queda la parodia y la burla como cínicas respuestas, como desesperados efugios. ${ }^{14}$

En fin, la actividad creadora deviene fenómeno necesario, individual (c. 1629) y lúdico (c. 12); a través del cual se transmite una visión del mundo original, homologable únicamente en términos de ideología profunda con la de otros individuos, y fundamentalmente problemática; visión sólo comunicable artísticamente a aquellos que posean la inteligencia, la conciencia del mundo o la intuición suficiente para percibir dicha complejidad, sin mediación totalizadora o unilateral que lo impida, cualquiera que sea la naturaleza de tal mediación. En ello reside la radical "actualidad" del Libro del Arcipreste, y, por ello, su autor se nos antoja un hombre de nuestro tiempo.

\section{Povzetek}

\section{JUAN RUIZ, ČLOVEK NAŠEGA ČASA}

Juan Ruiz, Arcipreste de Hita (arhiprezbiter iz Hite), Kastiljec iz 14. stoletja, sodobnik Petrarke in Bocaccia, je morda "prvi moderni človek" v Kastilji, kajti konflikti, ki jih prikazuje v svojem življenjskem delu El libro de Buen Amor, so popolnoma moderni.

Vendar ga jezikovna in tehnična plat njegovega dela, ki je še vedno zakoreninjena $\mathrm{v}$ tradiciji starega srednjeveškega pesništva klera mester de clerecía, neizogibno veže na srednji vek. Ravno to je morda bistveno protislovje tega temeljnega dela kastiljske književnosti.

Avtor članka je želel prikazati nekatere od teh konfliktov: napetosti med vero in razumom, med željo in resničnostjo, med pričakovanji posameznika in neizogibnim neuresničenjem le-teh, med strahom in občutkom za tveganje, med ljubeznijo in smrtjo, zadnjo neizpodbitno resnico, ki razgalja varljivi videz, pod katerim se skriva bistvo človekovega obstoja.

ciertos seres humanos para la felicidad en un mundo cuyas leyes de intercambio ya no dominan, o les son hostiles.

${ }^{14}$ Sobre la respuesta paródica a la angusita, Deyermond, HLE, Ariel, Barcelona, 1973. Volumen I, p. 206. Y Rafael Lapesa, en su artículo sobre el tema de la muerte en el Libro del Arcipreste, pp. 55 y 56 . También sería interesante comprobar el tratamiento que Unamuno da a este asunto en su novela Niebla: la ironía extrema, el sarcasmo y lo grotesco como alternativa posible, acaso "única", al conflicto existencial (pp. 40 y 42 en la edición Alianza Editorial, № 1189). 